\title{
Relational pedagogy and the Arts
}

\author{
Deborah Fraser, Graham Price, Viv Aitken, with \\ Gay Gilbert, Amanda Klemick, Lisa Rose, and Shirley Tyson
}

$\mathrm{I}$

$\mathrm{t}$ is through relationships with others that we discover much about ourselves. Indeed, much of who we are and how we learn is relational (Bishop \& Berryman, 2005; Buber, 1970; Erricker, Erricker, Ota, Sullivan, \& Fletcher, 1997; Gibbs, 2006; Noddings, 2003; Shields \& Edwards, 2005). Our need for relationships and social contact is natural and life enhancing, and to ignore this need is to risk our health and wellbeing: "It is a clinical fact that people who lack relationships get sick more often and recover more slowly than people surrounded by family and friends" (Palmer, 1998, p. 65).

Social relationships are an important catalyst and context for learning in classrooms. For example, the gains for children who have positive relationships with peers can include achievement as a result of "enhanced opportunities to exercise behaviours related to social, emotional and cognitive growth" (Newcomb \& Bagwell, 1996, p. 317). In addition, children's relationships with their teachers also impact on how they access curriculum, how they feel about themselves as learners, and often influence how engaged they become at school (Bishop \& Berryman, 2005).

This article explores the notion of "relational pedagogy" in the Arts (drama, dance, music, and visual art) starting with the teacher-child relationship, peer relationships, and building communities of enquiry. It also argues, however, that there is more to relational pedagogy than the social aspects (relationships with teachers and with peers), and that relational pedagogy also comprises relationships with self and with the art-making process. These are often inextricably related, especially in classroom environments that encourage communities of inquiry alongside a focus on the exploration of the potential of various media.

Most contemporary theories on learning acknowledge that learning is more complex and multifarious than any simple cause-and-effect analogy. Teaching in the Arts, described in terms of relationship pedagogy, might be characterised in Bergum's description of the teacher's role: "watchfulness, trust of the student, letting the student learn, with the goal of opening the space for the student [to] come into one's own" (2003, p. 122). Bergum's interpretation certainly challenges traditional concepts of power and traditional notions of knowledge construction. On the other hand, it also seems to imply that teachers are merely passive observers of students' learning and this extreme, too, is not sufficient if learning is to be enhanced. What then does "a watchful opening of the space for the student" look like and what is the teacher's role in such a pedagogy? This article outlines the multiple relationships through which children learn in the Arts, with implications for teachers.

A brief overview of an Arts research project is provided next and is followed by an exploration of relational pedagogy in and through the Arts.

\section{Methodology}

The Art of the Matter ${ }^{1}$ project comprised 10 primary school teacher researchers from eight schools, with classes of children across the Years $0-6$ age range, working alongside three university researchers and two consultants over a period of two years (2005-2006).

The design of the study drew on ethnographic, case study, self-study, and action research traditions of educational research. The case studies were devised from an amalgam of classroom observations, work samples, surveys, interviews, and reflective self-study comments. Perspectives from teachers, university staff, children, and school policy documents helped to build rich, triangulated sense-making accounts of current practice (Stenhouse, 1980). 


\section{Findings}

Emerging from the study was the underlining theme of the relational nature of teaching and learning in and through the Arts. A series of significant relational contexts were manifest in a variety of ways. The most obvious was the child-teacher relationship, which is discussed first. However, equally potent relationships between children and between the child and the various arts media also emerged. Moreover, the Arts provided opportunities for children to further their relationships with an intrapersonal world in multiple ways.

\section{Child's relationship with the teacher}

Relational pedagogy as a concept tends to refer mostly to the relationship between teacher and child, and even a cursory glance at most texts on teaching and learning reveals chapters on such topics as interpersonal communication, management of behaviour, attending to social and emotional dimensions, promoting discussion and interaction, and so forth (e.g., Good \& Brophy, 2000; Groundwater-Smith, Ewing, \& Le Cornu, 2003; McGee \& Fraser, 2001). These texts emphasise that the main pedagogical relationship is the one between teacher and child. Just how this might manifest in the Arts requires closer examination.

If we are to assert that the Arts should tap the personal and emotional world of children (Richardson, 1988), and that children "of necessity, develop from both the inside out and the outside in" (Eisner, 2002, p. 93), then the teacher's role must be particularly finely tuned in order to build the trust necessary for children to risk the exposure, expression, and depth of emotional engagement that is manifest in a rich Arts experience. The relationship between teacher and child, while important in all subjects, is emphasised in the Arts where the personal, emotional, and psychological world of the child is explored, may be revealed, and ideally enhanced. If the emotional world of the child is exposed, then an atmosphere of trust is vital to ensure safety during the process. But there also needs to be some challenge or "charge" (Palmer, 1998) so that children grow in their skills and abilities. Moreover, relational pedagogy in Bergum's (2003) terms is about opening a space for children to come into their own. Just how that can manifest is described next in reference to teacher-in-role.

In the Art of the Matter project, a principal focus for the teacher researchers working in drama was the strategy of teacher-in-role.
Teacher-in-role is a key strategy in the approach known as "process drama", in which the teacher enters the imagined world as fellow participant with the children (Bolton, 1998; O'Connor, 2006; O'Toole \& Dunn, 2002). Teachers found that by entering into a role alongside the children, they could "open space" for learning in a number of ways. For one thing, during the improvisation that is necessarily part of teaching-in-role, teachers found they took risks alongside the children. They were able to model participation, commitment, and use of drama techniques. Teachers also found they ceded decision-making power to the children more readily when in role.

For example, a challenging synchronicity arose during the project in a class of Year 3 children where the teacher researcher had adopted the role as "the sun" within a retelling of the Māori legend "Maui and the Sun". A grey day was suddenly illumined as actual sunlight burst into the classroom at precisely the same moment that the teacher entered in her role as the sun. Presumably, in a desire to solve the issue of why there were suddenly "two suns", a child loudly volunteered, "That must be your mother!" and the teacher fluidly adopted the new role cast upon her by the children. Through child initiative the entire drama shifted into the impromptu use of a phone conversation convention to invite "the mother" (the sun outside in the sky) to afternoon tea with the class. When the child disappointedly said, "But we don't know the number!" the teacher continued to build belief through an impromptu: "Oh yes we do, it's 0800 SUNSHINE." The drama continued to explore mother-daughter relationships that held rich personal relevance, rather than pursuing the planned power narratives of Maui, his brothers, and the sun. The child's response to the sun's arrival demonstrated the level of commitment and conviction the child had reached, and her evident sense of "permission" to create and make "offers" within the drama. The teacher's response within role deepened the commitment and initiative of this child, while her use of the phone call convention allowed the child to deepen the idea and bring the rest of the group along with her. According to Prior (2001) the major challenge for the teacher is to let go and share "the created world with their students" (p. 28). Where this kind of power sharing occurs, the teacher no longer "owns" the drama; rather, it is co-constructed.

To summarise, teacher-in-role was seen as a highly valuable tool in fostering teaching relationships where children were empowered to deepen their ideas. At its best, teacher-inrole can epitomise Gallagher's (2000) ideal of the Arts teacher as "the person in the equation who creates the spaces of possibility, who does not find solutions but nurtures the questions, while asking the learners to bring what they already know to bear on what they are learning" (p. 114). Of course teachers in other Arts can "open spaces" for students in other ways and this article goes on to describe how various other Arts teachers on the project engaged and collaborated with their students in very meaningful ways. However, it is fair to say that in this project, the sense of collaboration and engagement, of "being with" the students, was very striking in drama and less explicit in the other Arts. Teacher-in-role is a model of joint inquiry where teacher and children collaborate and where children see their teacher engaged in Arts thinking and activity alongside them. We suggest that these paradigms are core to relational pedagogy and have implications for teaching across all the Arts and beyond.

\section{Child's relationship with peers}

Relational pedagogy is also about collaboration with peers. In all of the art forms the project found evidence of children guiding, instructing, and advising each other, either incidentally or more explicitly. There was evidence of children actively seeking feedback from each other and responding to this, for example, during painting asking, "Does this look like water to you?" Peers were instrumental in a variety of ways. One teacher researcher on the project regularly nurtured peer feedback in the visual arts by frequently using the questioning stem: "Does anyone have a challenge for ...?" The challenges were invitational rather than mandatory, and it was noted that children in the class felt empowered to sidestep teacherinitiated challenges and make their own.

In another significant innovation within a dance context, a teacher researcher introduced nonverbal feedback, employing dance movements to convey to children what she had witnessed and what she thought about their dance. In no time at all, the children volunteered to give nonverbal feedback to each other. This quickly grew in popularity and scope as the children's confidence and skills grew. Once the children became au fait with giving and receiving nonverbal feedback in dance, the teacher researcher wanted to extend the process to the giving of suggestions for improvement or "feedforward". The dance lessons still featured some verbal discussion, especially when recapping main ideas with the 


\section{In one of the}

\section{project's schools,}

the notion of

"peer support"

and tutoring was

an established

\section{ritual of practice,}

and was

\section{interpreted as}

\section{an informal and}

\section{ever-changing}

network of

\section{interdependent}

\author{
support
}

\section{rather than}

\section{a formalised}

\section{sustained paired}

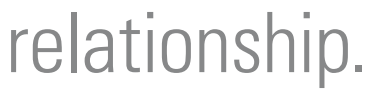

class, outlining changes groups had made to their dances, and refining ideas.

As with the nonverbal feedback, when children were offering nonverbal feedforward to their peers, checks were made to ensure those receiving the suggestions were clear as to what was meant. The children volunteered through dance feedforward refinements such as the awareness of using different levels in dance, the need to spread out to give group members room, and to vary the choreography to include individual moves amongst group moves. It seemed that nonverbal communication encouraged performers and spectators to pay sharper attention to the general coherence and "messages" conveyed. This was inferred from their stillness, lack of fidgeting, and absorbed silence while watching their peers compared to competing for attention when feedback sessions were more verbal. It was also evidenced by their increased responsiveness to verbally interpret and adopt or adapt what was conveyed. As a result of these trials, nonverbal peer feedback and feedforward through dance became a regular part of the dance lessons, with the class buying into an effective culture of nonverbal communication. The children also considered the timing of giving feedback and feedforward by sharing during lessons when groups specifically asked for it, and not just at the end, so that ideas could be developed further in class. Moreover, children created an intriguing further extension to the nonverbal "dialogue" through spontaneously dancing their delight or confusion, in response to the feedback and feedforward. The children's comments on this nonverbal dance communication included:

I like it because I could see what my

dance looked like to someone else.

I found it better than being told because it was a surprise.

In visual art in another classroom, the whiteboard was used to note children who could be consulted with if any child in the class had a problem with their art, whether it be colour mixing, creating hues and tones, media control, achieving accuracy, or a sense of distance. The teacher researchers who actively encouraged this peer teaching provided clear messages about learning. They repeatedly conveyed and affirmed that teaching comes from multiple sources and that learning from peers is part of the many possibilities available. They often deferred an enquiry to a child "expert" and gave children multiple pathways to seek support. Such classrooms become communities of learners, in which both teachers and children can grow and develop through reciprocal and mutually enhancing relationships. Noddings (2003) stated that the relational view of teaching and learning emphasises this interdependence wherein people are mutually supportive of each other. The fostering of a community of learners (Rogoff, 2003) enables "natural" formations of groups around problems that require the pooling of expertise between children. In addition, the "experts" were not always the same children each time, as new experts kept emerging during different processes of art making.

The involvement of peers as teachers also mitigates the problem of one teacher attempting to meet all the fine-tuned needs of individuals, which can vary greatly across 30 children in any class. In one of the project's schools, the notion of "peer support" and tutoring was an established ritual of practice, and was interpreted as an informal and ever-changing network of interdependent support rather than a formalised sustained paired relationship. As such, formal training was not required but frequently modelled from a variety of sources. Year 6 children demonstrated sophisticated ways of patiently demonstrating possibilities, giving opportunities for repetition, checking understanding, and then letting the learner take responsibility for their own decisions with the invitation to seek further help once this had been tried. Such maturity of insight and timing could only have come from the embedded observation and daily experience modelled by their own teacher.

When a commonly held problem emerged, a class conference around the issue was called. During such conferences the teacher usually took a more leading role in probing understanding, making suggestions, and building on what a variety of children offered. She also called upon some children to demonstrate or display through their art work in progress a concept that others had overlooked. The teacher (in such instances) is responsive to children's actualneeds rather than instructive about their perceived needs. This distinction is important if teachers are to avoid teaching what children already know (Nuthall, 2001) or, alternatively, teaching what children are not yet ready for. Moreover, the university researcher was occasionally included in consultation for suggestions when the teacher researcher was unsure about unfolding directions, creating a wider community of inquiry beyond the classroom itself. Again, the notion of seeking guidance came from a need-to-know basis and not from a top-down model of what the 
expert thinks is required. This "naturalised" inclusion of expertise beyond the classroom was consciously extended to teacher colleagues and invited guests within the programme throughout the school year.

From a sociocultural perspective, learning and teaching in classrooms can be considered a dynamic, participatory process that occurs and is influenced by the personal, the interpersonal, and the institutional (Rogoff, 2003). These three "lenses" are mutually responsive and cannot be neatly separated (Sewell, 2006). In other words, studying children's learning in the Arts cannot be severed from the social and cultural context in which that learning takes place. Those classrooms that foster a community of learning convey a seamless and dynamic relationship between teacher, learners, and the Arts media they are working with. Moreover, the social and cultural context in which learning takes place, both transforms, and is transformed by, the way in which people interact and participate within that context.

\section{Child's relationship with the art medium}

Another relational aspect of note, and one frequently missing from the general literature on learning, is the child's relationship with the art medium itself. Engaging with paint or sculpture, drums or shakers, spoken thoughts or a hot-seating activity, changing dynamics within dance music requires immediacy and sensitivity of response from children. Through such repeated experiences, children learn to trust their awareness of nuance and mood. As Eisner (2000) claimed, the Arts "traffic in subtleties" (p. 9) and the art medium worked with provides direct cues to the exercise of subtlety. Children are able to appreciate these subtleties more when they are given the time and opportunity to explore what their body, instrument, role, or art material can do. The Cartesian notion of mind-body split is disrupted in the Arts as knowing the world through the body (Merleau-Ponty, 1968) is the primary mode and facilitates important Arts knowledge (Juntunen \& Hyvonen, 2004).

Bayles and Orland (2001) noted that "vision is always ahead of execution - and it should be; knowledge of materials is your contact with reality, and uncertainty is a virtue" (p. 15). It is only through exploring the art mediums in a low-risk, high-engagement way that children can learn from what the medium is conveying to them. For example, in the project we observed children discovering that colour flow works better with broad rather than fine movements.
This important insight emerged when one class tried to transfer finely drawn images of marine animals into painted compositions using colour flow. The medium chosen required different skills and the children's realisation of this was an important insight to what art media "tells" us about its properties. Responsiveness to such nuance makes all the difference between crippling frustration and breakthroughs in the face of challenge. Another example emerged in a dance class. Upon viewing their dance rehearsal on video, a group of children suddenly noticed that using different levels in space made their dance look more interesting. While immersed in "doing", they were unable to view the overall effect, but when viewing themselves as a group they were able to appreciate the gestalt of their choreography. The art medium, in this case dance, is nonverbal and as such requires an awareness of movement, shape, gesture, and the body in action. Such forms expressive of human feeling are not mediated through words necessarily, and as Langer (1953) noted, the nondiscursive nature of the Arts enables ways to convey the verbally inexpressible.

When children reach the limits of their current ability they need scaffolded assistance to solve the new problems they may encounter, as well as opportunities to consolidate new discoveries. Eisner (1972) commented on the interdependent nature of form, idea, and media that children acquire through exploration, accident, and play. Researchers in the project also noted that the wider learning environment played a significant role in children's creativity. Not so much the physical environment as the psychological environment, in terms of levels of teacher support, personal safety, a sense of expectations and standards, and permission to make mistakes and experiment. In low-risk environments, children are more likely to try new techniques and push the boundaries of what is possible. Freed from the constant surveillance of the teacher or evaluative judgements, there is the opportunity to immerse oneself in a world unshackled by constraints and expectations. For example, researchers in music noted the importance of unstructured free play opportunities for children's creativity in music while in visual art, children appeared to benefit from opportunities to work in their own way in their own time, seeking help when required.

If teachers are to help children understand and respond to the medium they are working in, they need uninterrupted and repeated engagement with it. Such engagement is relational in that it is through the encounter that children come to know the strengths, limits, and possibilities of themselves and their medium. This highlights how vital it is for children to have Arts experiences that allow this learning from and about the medium concerned. And in making qualitative judgements "one knows one is right because one feels the relationships. One modifies one's work and feels the results" (Eisner, 2004, p. 5). Immersion in art making allows the development of such discernment which is highly cognitive but not formulaic.

\section{Child's relationship with the self}

Relational pedagogy as a concept also has relevance for a child's relationship with him or herself. This is particularly so in the Arts, where children's selves are central. As art makers, children express themselves: their ideas, emotions, and points of view. They may also experience a moulding and redefining of their selfhood through the arts experience. In drama, children can "walk in the shoes" of someone new: someone who is not constrained by the child's current identity, nor by other people's expectations. Through drama, too, children can visit times and places beyond the here and now. They can reinvent themselves through role and they can take risks in a safe and encouraging environment. All this helps children appreciate their potential and not be limited by the daily assumptions of who they are.

This project found that through drama children were able to step into new roles that not only challenged themselves, but also changed the perception and expectations of their teachers. The teacher researchers commented on how many of the children grew socially in unanticipated ways. They noted some shy children becoming braver, quiet children being more assertive, and disruptive children learning to become more focused and engaged. In addition, boys were witnessed playing the roles of females and vice vers $a$ without self-consciousness. For example, one rather shy and reticent boy became Jack's mother, in "Jack and the Beanstalk". To deepen the quality of his initial, rather timid response, the teacher came out of role to model and support his confidence in his role as the mother. After several repetitions focusing on voice and gesture, as well as his innate knowledge of "mother", the boy in role as mother was able to admonish Jack with a strident voice to, "Go and sell the cow!", shaking his finger emphatically as he did so. Such transformations require both trust in the process of the drama and risk of the 
public scrutiny of one's constructed identity. The risk of exposure is lessened, however, through the taking of a fictional role, giving license for more freedom in identity.

Another example emerged when children in one class were visited by a teacher researcher in role as Mrs Glow: a property developer wanting feedback on her plans for the Waitomo caves. She suggested that the Waitomo caves should be gutted and turned into a holiday theme park. At first the children were excited by the prospect but slowly, a few dissenting voices emerged about the ethical and environmental impact. When Mrs Glow proposed that the real glowworms would be replaced by fake ones one child exclaimed, "But you can't lie to the public!" Another child who was disturbed about the life of the caves suggested, "You might like to build your adventure caves in the volcanic caves of Rangitoto. They aren't as old as our limestone caves and don't have life forms already in them." Here the "disruption" of teacher-in-role allowed students an agency they would usually be denied in the classroom-few children would feel sufficiently empowered to speak like this to a "real" classroom visitor. Teaching-in-role can "open up" spaces for children where their level of status, personal, social, and ethical responsibility, and even knowledge can be higher than that of the teacher role.

As Neelands (2004) attested, the "rhetoric" of stories of "transformation" associated with experiences of drama may be difficult to prove scientifically, but such stories are certainly widely reported, including by teacher researchers on this project. Similarly, children can discover things about themselves through their visual art, their music, and their dance. They learn about persistence and risk taking as much as they learn about rhythm, tone, colour mixing, and bodily expression. And because the Arts have the potential to tap memories and feelings, construct tangible records of changes, children can deepen their understanding of who they were and are becoming. Noddings (2003) noted that a relational view of learning and teaching acknowledges that we "are constructed through encounters with other bodies, objects, selves, conditions, ideas and reflective moments with our own previous selves" (p. 158).

At times, the child's relationship with self, with the medium, and with others in the room can reach a point of balance, where all seem to work together to produce a deeply personal relationship with the process of creating. In another study (Fraser \& Grootenboer, 2004), the Arts were recognised as a vehicle through which children became quietly absorbed in the process of creating to the extent that absorption in the moment was paramount. Sarah, the teacher, noted:

I think the Arts generally are a great opener for feelings of emotion and things and often, if we're talking about moments ... motivated by the arts: [music] dancing, drama, visual art, the act of doing visual art-painting or whatever. There's a hush that descends on the classroom and everyone is so absorbed in what they are doing and you don't often see that in other subjects. That is their own piece of work and it's their own expression and it's probably one of the most spiritual times in the curriculum for me, is seeing each child producing something of themselves. (p. 316)

This teacher highlighted the flow effect (Csikszentmihalyi, 1996) that occurs when children (and adults) are fully immersed in an activity that challenges and absorbs them, in this case enabling the children to express themselves creatively. This level of absorption is indeed the aim of teachers when they plan lessons but the achievement of such focused concentration with children during class can be elusive. Much of what we do in the Arts does not require verbal interaction and much can be expressed through silence, gesture, absorption in the physical act of doing, and creating. The outcome is unknown and minute by minute the art form is giving feedback to the child who, in interaction with the medium, develops from the "inside out, and the outside in" (Eisner, 2002, p. 93). The unconscious nature of the process liberates children to explore the art form alongside exploring their own skills and talents. The Arts offer opportunities for individual absorption into the mythic world of dream and reverie, so important for access to the unconscious (Claxton, 1998) and the development of the self. Through the Arts children can become more qualitatively intelligent, as working in an art form cultivates the integration of both thinking and feeling (Eisner, 2004).

\section{Conclusion}

It is in the encounter that we come to know and understand each other (Buber, 1970), and such encounters are the hallmark of effective teaching-learning relationships. The I-Thou relationship Buber writes of is a complete engagement with the other, be it person, animal, object, plant, or events, "to connect, to be one, with another person, a tree, a work of art ..." (Noddings, 2003, p. 170). Frederick Franck (1973) in The Zen of Seeing alludes to this goal:

Instead of the pleasures of so called selfexpression, you will discover a greater one: the joy of letting a leaf, a branch, express itself, its being, through you. In order to reach that point you'll have to see that which you are drawing, whether leaf, plant, or weed, as the most important thing on earth, worthy of your fullest deepest attention. (p. 24)

It is this broader view of relational pedagogy that is evident in the Arts and is relevant for all learning. It is important to acknowledge that the nature of learning in the Arts is not solely one of teacher-child or even subject-child though these are crucial. Such paired notions of relationship miss the constellation of ongoing encounters children are having while learning. We suggest that children also learn through relationships with the art medium itself, relationships with their peers, relationships with themselves, with their creative process, with their environment, and with other factors that arise in the dynamic flux of a child's life. Drawing upon this wealth of influences enables a deeper understanding of learning in and through the Arts.

\section{References}

Bayles, D., \& Orland, T. (2001). Art \& fear: Observations on the perils (and rewards) of artmaking. Santa Cruz, CA: Image Continuum Press.

Bergum, V. (2003). Relational pedagogy. Embodiment, improvisation, and interdependence. Nursing Philosophy, 4(2), 121-128.

Bishop, R., \& Berryman, M. (2005). The Te Kotahitanga effective teaching profile. Spanz Journal, 25-37.

Bolton, G. M. (1998). Acting in classroom drama: A critical analysis. Portland, ME: Calendar Islands.

Buber, M. (1970). I and thou. New York: Charles Scribner's Sons.

Claxton, G. (1998). Hare brain tortoise mind: Why intelligence increases more when you think less. London: Fourth Estate.

Csikszentmihalyi, M. (1996). Creativity: Flow and the psychology of discovery and invention. New York: HarperCollins.

Eisner, E. (1972). Educating artistic vision. New York: Macmillan.

Eisner, E. (2000, January). Ten lessons the Arts teach. Proceedings from an invitational meeting for education, arts and youth funders: Learning and the Arts: Crossing boundaries (pp. 7-14), Los Angeles. 
Eisner, E. (2002). Arts and the creation of mind. New Haven: Yale University Press.

Eisner, E. (2004). What can education learn from the Arts about the practice of education? International Journal of Education and the Arts, 5(4), 1-12.

Erricker, C., Erricker, J., Ota, C., Sullivan, D., \& Fletcher, M. (1997). The education of the whole child. London: Cassell.

Fraser, D., \& Grootenboer, P. (2004). Nurturing spirituality in secular classrooms. International Journal of Children's Spirituality, 9(3), 307-320.

Franck, F. (1973). The Zen of seeing: Seeing, drawing as meditation. New York: Knopf, Random House.

Gallagher, K. (2000). Drama education in the lives of girls: Imagining possibilities. Toronto: University of Toronto Press.

Gibbs, C. (2006). To be a teacher: Journeys towards authenticity. Auckland: Pearson.

Good, T. L., \& Brophy, J. E. (2000). Looking in classrooms (8th ed.). New York: Longman.

Groundwater-Smith, S., Ewing, R., \& Le Cornu, R. (2003). Teaching: Challenges and dilemmas (2nd ed.). Southbank, Victoria: Thomson.

Juntunen, M., \& Hyvonen, L. (2004). Embodiment in musical knowing: How body movement facilitates learning with Dalcroze Eurhythmics. British Journal of Music Education, 21(2), 199-214.

Langer, S. (1953). Feeling and form: A theory of art. London: Routledge and Kegan Paul.
McGee, C., \& Fraser, D. (Eds.). (2001). The professional practice of teaching (2nd ed.). Palmerston North: Dunmore Press.

Merleau-Ponty, M. (1968). The visible and the invisible. Evanston, IL: Northwestern University Press.

Newcomb, A. F., \& Bagwell, C. (1996). The developmental significance of children's friendship relations. In W. M. Bukowski, A. F. Newcomb \& W. W. Hartup (Eds.), The company they keep: Friendship in childhood and adolescence (pp. 289-321). Cambridge, USA: Cambridge University Press.

Neelands, J. (2004). Miracles are happening: Beyond the rhetoric of transformation in the Western traditions of drama education. Research in Drama Education, 9(1), 47-56.

Noddings, N. (2003). Happiness and education. New York: Cambridge University Press.

Nuthall, G. (2001, December). The cultural myths and realities of teaching and learning. Paper presented at the New Zealand Association for Research in Education: The Jean Herbison Lecture, Christchurch.

O'Connor, P. (2006, Autumn) Process drama and learning for now. Retrieved 10 October 2006, from www.mindnet.org.nz

O’Toole, J., \& Dunn, J. (2002). Pretending to learn: Helping children learn through drama. Frenchs Forest, NSW: Pearson Education.

Palmer, P. J. (1998). The courage to teach: Exploring the inner landscape of a teacher's life. San Francisco: Jossey-Bass.
Prior, R. (2001). Tension, power and control: Creating effective participatory drama. NADIE Journal, 25(2), 23-33.

Richardson, E. (1988). Children with a gift in writing: Book two. Henderson: Richardson Printing.

Rogoff, B. (2003). The cultural nature of human development. Oxford: Oxford University Press.

Sewell, A. M. (2006). Teachers and children learning together: Developing a community of learners in a primary classroom. Unpublished doctoral thesis, Massey University, Palmerston North.

Shields, C., \& Edwards, M. (2005). Dialogue is not just talk: A new ground for educational leadership. New York: Peter Lang.

Stenhouse, L. (1980). The study of samples and the study of cases. British Educational Research Journal, 6(1), 1-6.

\section{Note}

1. Art of the Matter was a collaborative Teaching \& Learning Research Initiative (TLRI) project administered by the New Zealand Council for Educational Research (NZCER) and based in Hamilton, New Zealand. For more background information on the research project and its methodology, see http://education.waikato. ac.nz/research/project/index.php?id=34

Deborah Fraser is an associate professor in the Department of Human Development and Counselling, School of Education at the University of Waikato. She has directed five externally funded research projects and published widely in a variety of areas including creativity, metaphorical writing, and spirituality. Email: deborahळwaikato.ac.nz

Graham Price is a senior lecturer in the Arts and Language Department, School of Education at the University of Waikato. He has directed professional development projects in the Arts and published resources for generalist primary teachers' practice in the visual arts. He has also researched the influence of art education history on children's approach to artworks.

Viv Aitken lectures in drama in education at the University of Waikato. A passionate advocate for drama in educational contexts, Viv contributes to preservice and inservice training for teachers from early childhood to secondary level. Viv's research interests include: audience response theory, process drama, drama and special needs, teaching in role, and theatre in education.

Gay Gilbert (Hillcrest Normal Primary School)

Amanda Klemick (Piopio School)

Lisa Rose (Tauriko School)

Shirley Tyson (Hukanui School) 